Professional papers and workshops

This statement certifies that the following paper was conceived and written by the author alone. All information and ideas from others are referenced.

Author signature

Name Julie Granger

\title{
Allusions, Illusions and Learning Integrating story into the broader curriculum
}

\author{
Julie Granger \\ Teacher Librarian \\ Kanahooka High School \\ Australia
}

The workshop will be a visual presentation covering the rationale for a unit of research that involves integrated learning/curriculum and concentrates on critical literacy. The presentation will also involve a complete example unit and accompanying course booklet. Participants will be involved in a handson evaluation of the unit presented and assess its suitability to adapt to other "core literature genres". The unit of work involves the "multiple faces of literacy: Reading. Knowing. Doing." at the practical teaching level.

The aim is to show how to use texts from "classic fiction" in research units, as vehicles for learning, not only about the texts themselves, but also about their wider cultural significance and associated literary forms, as well as these stories represented in other media. The unit attempts to place everything examined in a meaningful context and to provide opportunities for students with diverse learning styles to enjoy the unit and to succeed. The objective is to make classic stories the integrating vehicles for learning, and so change them from literary "illusions" to "allusions" once more, therefore showing that the "critical literacy" approach can use traditional literature or story in teaching.

\footnotetext{
Allusions and Literacy

I have long held the belief that Literacy levels can be significantly affected by ignorance of allusions to literature, in what is read. Not only have many parents stopped reading to their children the traditional bedtime story, but also many of those who continue to do so have substituted the old favourites for some of the new and often wonderful, picture books currently available. Modelling reading is great for encouraging in children the desire to read, but other patterns can be set down at the same time by choosing to read, at least some of the time, the "core genres of literature", which I believe, are critical to the development of the literate individual.

No, I am not suggesting that parents read the Bible to their babies or Tolstoy to their toddlers! However, it seems to me that not many children are taught, or read, Nursery rhymes anymore and most do not know the stories from Aesop's Fables or traditional Fairy Tales. This is certainly true of the majority of children that I now teach.
} 


\section{Literacy and Culture}

All here, l'm sure, would agree that important lessons for life are contained in these culture stories. These lessons are so important that authors continue to make reference to elements of them to a greater or lesser extent in much of contemporary writing. These stories are the common consciousness of culture. Without knowledge of the "core genres" one cannot be literate. This is true for all cultures - even and perhaps even especially, those that did not have a written language. Story was the means of passing on culture and history from one generation to another. Australian Aboriginal elders lament the fact that many of their people have lost the stories of the "Dreaming" and therefore their heritage. This may also be true to a greater, or lesser extent, in all cultural groups. In Australian society of the 1950's and '60's most children were encouraged by their parents to attend Sunday school. Parents who were not churchgoers themselves often sent their children along. The predominant activity at Sunday school was the telling of Bible stories. Most children were therefore exposed to the stories from both the Old and New Testament and would be able to recognise the many literary allusions to the Bible in their future reading. Although I have no hard evidence for lack of attendance at Sunday school these days, my observations lead me to believe that it has become rare, and anyway, that the current trend is for morality to be taught by reference to various episodes of TV sit-coms!

\section{Contemporary Illusions}

This malady of our time was encapsulated for me in a journalistically clever article in "The Weekend Australian", February 25-26, 2006, a magazine lift out from one of Australia's national newspapers. The writer, Susan Maushart, revealed herself to be culturally literate, but suggested that the current English poet laureate, Andrew Motion, is "more of a metaphor", because he suggests that contemporary children should read "classic" literature. She is a mother like myself and is no doubt stuck in the "quest" for just getting through each day to the "grail" of wine at dinner! The tenor of her article was that the poet laureate is out of touch, not only with children, but also with the realities of $21^{\text {st }}$ century life. I gleaned this from such phrases as -" Meanwhile back on planet earth". I guess she was suggesting that Andrew Motion himself is an anachronism. She thinks this because the texts he suggests children read are works of art and therefore considered difficult and elitist.

All I can say is that times have not changed all that much - these same texts were considered equally elitist and difficult by many when they formed a large part of the New South Wales English curriculum in the $50 \mathrm{~s}, 60 \mathrm{~s}$ and some of the $70 \mathrm{~s}$. What is different now is our lack of willingness to challenge students with tasks that risk disengaging them from learning.

This workshop aims to use some of these, so called, difficult texts as vehicles for learning, not only about the texts themselves, but also about their wider cultural significance. To try to place everything examined in a meaningful context and to provide opportunities for students with diverse learning styles to enjoy the unit and to succeed. My aim is to make classic stories the integrating vehicles for learning, and so change them from literary illusions to allusions once more.

\section{The Arthurian Legends as an integrating vehicle for a research unit}

The example is a unit of work using a "core genre" of the English speaking culture i.e. Arthurian Legends

The aim is to create a unit of work for 14 to16 year old students, (Library research), which integrates aspects of the wider curriculum and learning styles with the outcome of imbuing students with cultural ideas and images and improved reading and literacy skills. The Curriculum areas are as follows. For English, the poem The Lady of Shallot by Alfred Lord Tennyson, taught after the class has had ample exposure to several forms of the Arthurian story. All students would attend this class. Students would also be given choices of associated young adult fiction to read during the course of the unit and opportunity for discussion of the relation of the text to the legend would be provided. The Shallot 
series by Felicity Pulmann is particularly suitable for use with the poem and those students reading those books could report to the class how the poem and novels are connected. Other suitable novels would be the Avalon series by Marion Zimmer Bradley. And there are many others.

For History, it would be possible to include aspects of Roman Britain and Medieval Europe, connecting the fables and legends that are set in these times. For example, the story of Arthur is historically set in $6^{\text {th }}$ Century Britain, after the departure of the Romans, but the setting is predominantly medieval, reflecting the time in which most of the stories were written.

Geography can easily be integrated and always should be, by way of maps showing the locations of places of both the history and the stories. For example, maps of the known world in the period $500-$ 1200AD.

Mathematics can be involved in several ways that are limited only by the imagination of the students and the teachers. For example students could construct a time- line showing the possible historical King Arthur and also showing the different historical and cultural time elements written into the story. Mathematics and technology could be involved by the study and even construction of an Astrolabe. Science could be involved by looking at Alchemy and magic and postulating how they may have been the precursors of chemistry.

Religion study could look at the Celts (Druids and Wicca), Monasteries, and the medieval aspect of the stories and also a discussion of how the stories were influenced by Christianity, coming, as they obviously did from a Celtic tradition.

Music could be introduced in several ways. The simplest being the musical "Camelot", but musical instruments mentioned in the Arthurian Legends and those from Medieval Times could be examined. Visual Arts has a rich wealth to draw upon as so many artists over time have depicted the stories. Illuminated manuscripts would be another possible related area of study.

\section{The Planning}

It is clear that this is a massive task and that it would not be possible to teach it in the traditional lesson-by-lesson manner and that was never my intention. The desired path of most of this learning is one of revelation through research. The seeds are sown by the stories, presented in their various forms and followed up by a careful few motivating lessons on related poems or novels. The rest is a matter of the student's choice, the teachers filling the roles of advisers and facilitators.

Students choose from a grid based upon Bloom's taxonomy and Gardiner's Multiple Intelligences. They are able to work within their preferred learning styles. They are assessed and graded according to levels of difficulty on the Bloom's Taxonomy grid, i.e. as the activities become more difficult more credit points can be earned. The workshop provides a full copy of this rubric, as well as a work booklet, which explains and covers the unit of work.

The Arthurian Legends as an example of a core literary genre being used as an integrating vehicle is only one of the many that could be employed in the same way. I have many ideas myself and I hope that workshop discussion will be full of ideas for more.

\section{References}

Donnelly, Kevin (2005) Teach the simple joys of reading. Australian, The; 26/07/05 Features, pg. 013

Jones, Gary (2005) Literary theory in the middle years classroom: Challenges for students and teachers. Primary \& Middle Years Educator; Apr 2005 Apr2005, Vol. 3 Issue 1, p3-8, 6p, 1bw

McDougall, Bruce (2005) It’s Buffy versus the Bard. Daily Telegraph, The (Sydney); 23/09/200

Mackay, Hugh (2005) Learning is about a joy of good text. Sun-Herald, The (Sydney); 25/09/2005 
Mitchoff, Kate Houston (2005) Ignite the story within: A librarian makes a case for using storytelling to increase literacy. School Library Journal, 51, 2, 39-40

Parker, Michael and Williams, Lindsay (2005) What's all the fuss? Informed, critical learners, isn't that what democracy is all about? Independent Education, 35, 26-27

\begin{abstract}
Author notes
Julie Granger began teaching English and Ancient History in High Schools in Sydney, Australia in 1972. She combined teaching with child rearing for the next fourteen years when she decided on a change of direction. The decision to study Teacher Librarianship was based on her diverse interests in the visual arts, history and literature combined with a strong educational perspective. Independent learning skills has been the driving force of her personal educational philosophy ever since.
\end{abstract}


Reproduced with permission of the copyright owner. Further reproduction prohibited without permission. 